\title{
VEGF-A and blood vessels: a beta cell perspective
}

\author{
Willem Staels $^{1,2} \cdot$ Yves Heremans $^{1} \cdot$ Harry Heimberg ${ }^{1} \cdot$ Nico De Leu ${ }^{1,3,4}$ (D)
}

Received: 18 March 2019 / Accepted: 11 June 2019 / Published online: 14 August 2019

(C) Springer-Verlag GmbH Germany, part of Springer Nature 2019

\begin{abstract}
Reciprocal signalling between the endothelium and the pancreatic epithelium is crucial for coordinated differentiation of the embryonic endocrine and exocrine pancreas. In the adult pancreas, islets depend on their dense capillary network to adequately respond to changes in plasma glucose levels. Vascular changes contribute to the onset and progression of both type 1 and type 2 diabetes. Impaired revascularisation of islets transplanted in individuals with type 1 diabetes is linked to islet graft failure and graft loss. This review summarises our understanding of the role of vascular endothelial growth factor-A (VEGF-A) and endothelial cells in beta cell development, physiology and disease. In addition, the therapeutic potential of modulating VEGFA levels in beta and beta-like cells for transplantation is discussed.
\end{abstract}

Keywords Blood vessels $\cdot$ Diabetes $\cdot$ Endothelial cells $\cdot$ Pancreatic beta cells $\cdot$ Review $\cdot$ VEGF-A

$\begin{array}{ll}\text { Abbreviations } \\ \text { Ang } & \text { Angiopoietin } \\ \text { BOEC } & \text { Blood outgrowth endothelial cell } \\ \text { E } & \text { Embryonic day } \\ \text { FGF } & \text { Fibroblast growth factor } \\ \text { HGF } & \text { Hepatocyte growth factor } \\ \text { IBMIR } & \text { Instant blood-mediated inflammatory response } \\ \text { RTK } & \text { Receptor tyrosine kinase } \\ \text { VEGF } & \text { Vascular endothelial growth factor } \\ \text { VEGFR } & \text { Vascular endothelial growth factor receptor }\end{array}$

Electronic supplementary material The online version of this article (https://doi.org/10.1007/s00125-019-4969-z) contains a slide of the figure for download, which is available to authorised users.

Nico De Leu

Nico.De.Leu@vub.be

1 Beta Cell Neogenesis (BENE), Vrije Universiteit Brussel, Laarbeeklaan 103, 1090 Brussels, Belgium

2 Institut Cochin, CNRS, INSERM, Université de Paris, F-75014 Paris, France

3 Department of Endocrinology, UZ Brussel, Brussels, Belgium

4 Department of Endocrinology, ASZ Aalst, Aalst, Belgium

\section{VEGF-A and the VEGF family}

Vascular endothelial growth factors (VEGFs) are broadly expressed dimeric molecules that are structurally related by eight conserved cysteine residues that form a typical cysteine-knot structure [1]. VEGF-A is the founding member of the VEGF family, which also includes placental growth factor (PIGF), VEGF-B, VEGF-C, VEGF-D, VEGF-E and snake venom (sv)VEGF [1]. All VEGF family members signal by binding to cell surface receptor tyrosine kinases (RTKs) [2]. VEGF-A binds several RTKs, including VEGF receptor-1 (VEGFR-1, also known as Flt-1) and VEGFR-2 (also known as KDR or Flk-1), both expressed predominantly on endothelial cells that constitute the lining of blood vessels [2]. Although VEGF-A has higher affinity for VEGFR-1, its main signalling effects are conferred through VEGFR-2 [2]. In development and physiology, VEGF signalling coordinates vasculogenesis and angiogenesis by guiding endothelial cell proliferation, migration and survival, as well as vascular permeability [2]. Not surprisingly, aberrant VEGF signalling is therefore implicated in the pathophysiology of several diseases, including diabetes [2].

\section{VEGF-A and blood vessels in pancreas development}

Reciprocal interactions between endothelial cells and other cell types occur during ontogeny, specification and branching 
morphogenesis of a variety of tissues and organs, including the liver [3] and lung [4]. Likewise, vascular-derived signals play a pivotal role during pancreas development (Fig. 1). Pioneering work by Lammert et al showed that nonnutritional signals derived from aortic endothelial cells induce endocrine pancreas differentiation [5]. The dorsal endoderm of embryonic mice devoid of VEGFR-2 lacks endothelial cells and does not express Ptfla, Ins1 or Gcg [6]. Vascular signals take part in a relay pathway from the aortic endothelium to the dorsal pancreatic mesenchyme and, through fibroblast growth factor (FGF)-10 signalling, from the mesenchyme to the endoderm. These interactions are crucial for the maintenance of Ptfla expression and subsequent endoderm differentiation in the dorsal pancreas of embryonic day 9.5 (E9.5) [7].

While needed for induction of embryonic pancreas specification, blood vessels restrain outgrowth and morphogenesis of the pancreas epithelium during later development.
The trunk region (where bipotent progenitors of endothelial and duct cells reside) expresses higher levels of VEGF-A as compared with the tip epithelium (where acinar progenitors reside), resulting in increased vascularisation and decreased branching as compared with the tip epithelium [8]. VEGFA loss- and gain-of-function experiments in E12.5 pancreas revealed that hypovascularisation favours pancreatic branching and both exocrine and endocrine cell differentiation through the induction of carboxypeptidase A1 $(\mathrm{CPA} 1)^{+}$and PTF $1 \mathrm{a}^{+}$multipotent tip cells and of neurogenin $3(\mathrm{NGN} 3)^{+}$endocrine progenitor cells, respectively, while hypervascularisation sustains the primitive undifferentiated state of the tubular trunk epithelium [9]. Overexpression of VEGF-A in developing beta cells results in reduced beta cell proliferation at E16.5 and postnatal day 1 (P1) and in impaired islet cell clustering, culminating in a reduced postnatal beta cell mass. In contrast, increased

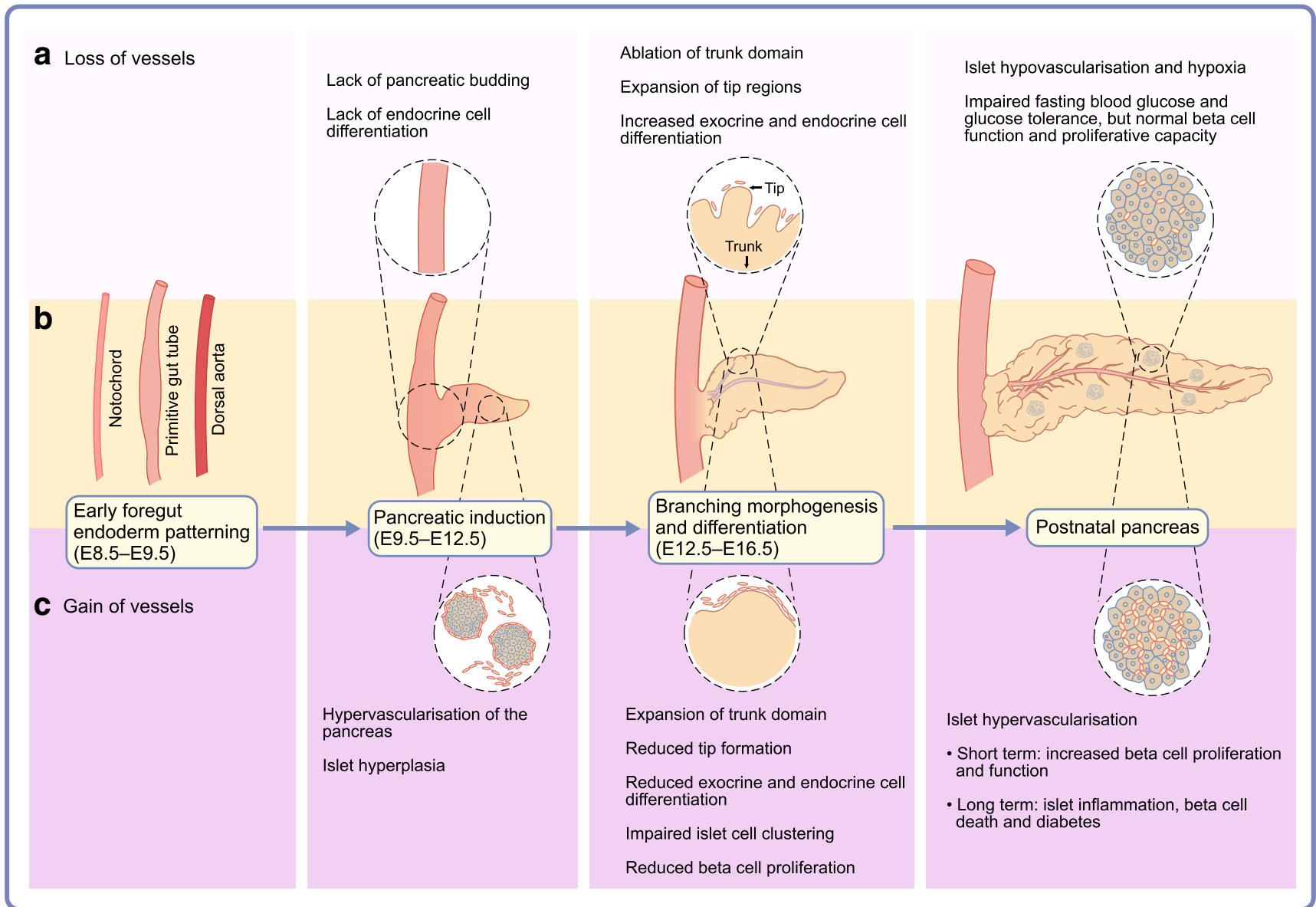

Fig. 1 The impact of loss or gain of blood vessels on pancreas development and function. (a) Loss of blood vessels, (b) normal vascularisation, and (c) gain of blood vessels. Blood vessels provide non-nutritional cues crucial for endocrine pancreas development and function. Loss of blood vessels during early pancreas development ( E9.5) inhibits normal pancreatic bud outgrowth and endocrine cell formation. Later on $(\sim \mathrm{E} 12.5)$, hypovascularisation promotes pancreatic branching and exocrine and endocrine cell differentiation, while hypervascularisation sustains the undifferentiated state of the tubular trunk epithelium. In the adult pancreas, islet hypovascularisation causes islet hypoxia and mild glucose intolerance, but the direct, deleterious effects on the beta cell are small. Adult islet hypervascularisation has time-dependent effects on the beta cell, initially increasing beta cell proliferation and function, while later on promoting islet inflammation and loss of beta cells. This figure is available as a downloadable slide 
expression of angiopoietin (Ang)1 or Ang2 in developing beta cells does not alter islet cell differentiation or morphology [10].

VEGF-A signalling and endothelial cells are crucial for pancreas specification, branching morphogenesis and both endocrine and exocrine pancreas differentiation.

\section{VEGF-A and blood vessels in adult beta cell physiology}

While islets of Langerhans in the adult pancreas are highly vascularised in general [11], species-specific differences exist $[12,13]$. Compared with humans, in the mouse islet vascular density is substantially higher and more tortuous $[12,13]$ and intra-islet blood vessels contain fewer smooth muscle cells [11]. Furthermore, mouse islet endocrine cells lack a basement membrane and directly interact with the vascular endothelial basement membrane, while in humans the islet endocrine cells are separated from the endothelial cells by a double basement membrane [14]. Several mechanisms, including angiopoietinTie2 signalling [10] and intra-islet biomechanical properties [15], are involved in the regulation of islet vessel density and in the crosstalk between islet cells and endothelial cells, but the role of VEGF-A has been studied most extensively. Both in human and mouse endocrine pancreas, VEGF-A is mainly produced by alpha and beta cells, functioning as an important regulator of the islet microvasculature [16]. Vegfa knockout in insulin-producing cells (RIP-Cre; VegfoxPlloxP mice) results in islet hypovascularisation, loss of endothelial fenestrations and decreased glucose clearance and glucose-stimulated insulin secretion but does not affect adult beta cell mass $[16,17]$ nor its capacity for expansion in response to insulin resistance, when stressed by a high-fat diet [18]. In line with these findings, we showed that adult mice with reduced intra-islet VEGF-A bioavailability through soluble (s)VEGFR-1-mediated scavenging show a rapid regression of intra-islet blood vessels with ensuing islet hypoxia, together with slightly increased basal and stimulated blood glucose levels [19]. The beta cell mass and basal beta cell proliferation of the mice remain unaffected. Furthermore, intra-islet hypovascularisation did not prevent beta cell proliferation after severe pancreas injury caused by partial pancreatic duct ligation or partial pancreatectomy [19].

The islet vasculature in adult mice undergoes dynamic and morphological changes in response to fluctuations in blood glucose levels and to intra-islet VEGF-A and insulin levels. Low glucose reduces intra-islet blood flow and decreases VEGF-A secretion in both cultured islets and purified beta cells [20]. Sustained hypoglycaemia results in apoptosis of endothelial cells and beta cells and in a reduction in beta cell mass which could be rescued by exogenous delivery of VEGF-A [21]. In contrast, hyperglycaemia by glucose clamp or by i.v. glucose injections significantly increases intra-islet blood flow [22]. Insulin plays a crucial role in these glucosemediated vascular adaptations since endothelial cell-specific insulin receptor knockout mice display decreased islet blood flow, blunted glucose-stimulated insulin secretion and glucose intolerance [23]. Mechanistically, vascular endothelial cellspecific phosphoinositide 3-kinase (PI3K) downstream signalling supports a normal islet vascular density and islet blood flow, in addition to maintaining a normal beta cell mass and function [24]. Of note, several other factors including gastrointestinal hormones, neurotransmitters and locally acting autacoids can influence islet blood flow [11].

VEGF-A and insulin signalling are crucial for adult islet vessel maintenance, blood flow and tight glucose control.

\section{VEGF-A and blood vessels in beta cell dysfunction and diabetes}

Type 2 diabetes is characterised by insulin resistance and beta cell dysfunction [25]. Vascular changes in peripheral insulinsensitive tissues, including decreased capillary density and recruitment, impaired blood vessel relaxation and proinflammatory activation of the endothelium, have been implicated in the pathogenesis of insulin resistance [26]. Although insulin resistance significantly affects the beta cell phenotype and can ultimately lead to beta cell dysfunction and exhaustion [25], elaborating on the peripheral vascular changes associated with insulin resistance falls beyond the scope of this review.

In addition, within the islets, a link between islet vessel density and beta cell dysfunction has been described. Islet hypovascularisation was correlated with beta cell loss and diabetes in Zucker diabetic fatty rats [27] and Otsuka LongEvans Tokushima Fatty rats [28], while mice fed a high-fat diet over 4 months showed increased islet VEGF-A content and islet hypervascularisation [29]. These findings were further elaborated by transgenic and viral vector-mediated overexpression of VEGF-A in beta cells, which resulted in islet endothelial cell accumulation, vascular leakage, inflammation and a subsequent reduction of the beta cell mass with onset of diabetes [29]. Consistent with these findings, we and other investigators observed a reduction in beta cell mass with ensuing glucose intolerance upon extended VEGF-A overexpression in beta cells $[30,31]$. These findings in rodents are in line with observations in the pancreas of individuals with type 2 diabetes showing increased intra-islet capillary density, 
Table 1 Upregulated genes in islet endothelial cells of rodent type 2 diabetes models

\begin{tabular}{|c|c|}
\hline Process & Genes \\
\hline Inhibition of fibrinolysis & Pai-1 \\
\hline \multirow[t]{3}{*}{ Vascular adhesion } & Sele \\
\hline & Pecam-1 \\
\hline & Vcam-1 \\
\hline \multirow[t]{2}{*}{ Renin-angiotensin system } & Ace-1 \\
\hline & Agtr-1a \\
\hline \multirow[t]{7}{*}{ Vascular tone/oxidative stress/angiogenesis } & Cox-2 \\
\hline & $\operatorname{Nos} 3^{\mathrm{a}}$ \\
\hline & $E d n 1$ \\
\hline & Ho-1 \\
\hline & Hif-1a \\
\hline & Nox-2 \\
\hline & Ptgis \\
\hline \multirow[t]{5}{*}{ Cytokines and growth factors } & $I l 1 b$ \\
\hline & Illra \\
\hline & Il6 \\
\hline & $T g f-b$ \\
\hline & $\operatorname{Tnf}-a$ \\
\hline \multirow[t]{3}{*}{ Chemokines } & Cxcll \\
\hline & Ccl2 \\
\hline & Mip-1a \\
\hline \multirow[t]{6}{*}{ Cellular pathways for cytokines and TLRs } & Casp1 \\
\hline & Tlr 2 \\
\hline & Tlr 4 \\
\hline & Myd 88 \\
\hline & $N F-\kappa B$ \\
\hline & $i N O S$ \\
\hline
\end{tabular}

Ho-1 is also known as Hmoxl; iNOS is also known as Nos2; Mip-1a is also known as $C c l 3 ; N F-\kappa B$ is also known as Rela; Nox-2 is also known as $C y b b$; Pai-1 is also known as Serpine1

Compilation of the results reported by Hogan et al. [33] and Lacraz et al. [34]

${ }^{\mathrm{a}}$ Increased in [34] but not different in [33]

TLR, Toll-like receptor

capillary thickening and fragmentation and islet fibrosis [13, 32]. Consequently, both islet hypo- and hypervascularisation seem to be correlated with beta cell mass loss in rodent models of type 2 diabetes. Besides changes in islet vessel density, alteration in expression of genes regulating islet blood flow and inflammation have been described in intra-islet endothelial cells in rodent models of type 2 diabetes [33, 34] (summarised in Table 1). In addition, chronic hyperglycaemia results in the accumulation of AGEs that contribute to endothelial cell dysfunction in both $d b / d b$ mice [33] and in type 2 diabetic patients [35]. Mechanistically, AGEs stimulate NF- $\mathrm{KB}$ activation, subsequent cyclooxygenase (COX)-2 activation and increased prostaglandin $\mathrm{E}_{2}$ synthesis resulting in endothelial cell dysfunction and apoptosis [36].
Type 1 diabetes mellitus is characterised by an autoimmune destruction of insulin-producing beta cells [37]. In the NOD mouse, a murine model of type 1 diabetes, this autoimmune process starts with a non-destructive stage characterised by an intact peri-islet membrane surrounded by predominantly antigen-presenting macrophages and dendritic cells, and later on by CD4 T cells, CD8 T cells and B cells [38]. This stage progresses to a second destructive phase during which cathepsin-producing macrophages destroy the peri-islet membrane. Next, autoreactive T cells are activated by antigenpresenting cells in pancreatic lymph nodes and migrate towards the islets to induce beta cell destruction, ultimately leading to clinical diabetes $[39,40]$. Aberrant islet microvasculature has been reported at this stage [41]. The endothelial cell layer that normally forms a barrier to blood leucocytes now displays antigen-presenting capacities and becomes permeable, thereby allowing $\mathrm{T}$ cells to extravasate into the islets and destroy them [41]. Chemokine-expressing perivascular $\mathrm{CD} 11^{+}$cells contribute to this process of $\mathrm{T}$ cell extravasation into islets [42]. Interestingly, increased VEGF-A expression originating from beta cells and inflammatory cells, including $\mathrm{CD}_{11 \mathrm{c}^{+}}$cells, promotes islet vascular remodelling in NOD mice. It has been reported that experimental interference with endothelial VEGFR-2 signalling prevents the increase in islet vascularity seen in untreated NOD mice, and impairs $\mathrm{T}$ cell trafficking, reverses insulitis and restores normal glucose control [43]. In contrast, other investigators found a decrease in islet vessel density in NOD mice [44]. Interestingly, immune intervention with anti-CD3 antibodies can normalise glucose control in NOD mice but fails to correct islet vessel density [44]. Both islet vascularisation and glucose tolerance were restored by increasing intra-islet VEGF-A levels through daily glucose injections for 14 days [44]. Finally, although few reports exist on the intra-islet vascular adaptations in the pancreas of patients with type 1 diabetes, islet vessels were recently shown to be smaller and more numerous than those observed in non-diabetic control individuals [45].

Vascular changes contribute to the onset and progression of type 1 and type 2 diabetes, and VEGF-A functions within a narrow physiological range to maintain islet homeostasis and function.

\section{Blood vessels in beta cell (re)generation}

We showed that short-term overexpression of VEGF-A in adult mouse beta cells indirectly stimulates their proliferation and protects them against alloxan-mediated diabetes [31]. Prolonged VEGF-A overexpression adversely results in murine beta cell loss and impaired glucose clearance [30]. However, restoring intra-islet VEGF-A levels to normal 
restores beta cell mass, function and islet structure. The remaining beta cells increase their proliferation rate and the overload of islet endothelial cells disappears [30]. This regenerative process depends on the recruitment of bone marrowderived macrophages and on endothelium-derived factors, including FGF-1, insulin-like growth factor (IGF)-1 and platelet-derived growth factor subunit B (PDGFB) [30].

Several other endothelial-derived factors have been suggested to modulate beta cell proliferation and function. In the endocrine pancreas of mice, endothelial cells establish a vascular niche by forming a basement membrane for endocrine cells. Herein, endothelial laminins connect with $\beta 1$-integrins on the beta cell surface to promote insulin gene expression and beta cell proliferation [46]. Also, vascular-derived collagen IV interacts with $\beta 1$-integrins on the beta cells to promote endocrine cell motility and function [47]. Aside from such direct crosstalk, paracrine interactions between endothelial cells and beta cells have been described. Endothelial cells produce connective tissue growth factor (CTGF) that, in turn, can upregulate positive cell cycle regulators and other factors involved in beta cell proliferation, including $\beta 1$-integrin and hepatocyte growth factor (HGF) [48, 49]. Of note, VEGF-A and insulin can trigger the release of HGF from endothelial cells which, in a co-culture system, stimulates rat beta cell proliferation [50]. The authors suggested that this VEGF-A/insulin-HGF pathway contributes to compensatory beta cell expansion during pregnancy [50]. However, in our model of conditional islet hypovascularisation through blocking VEGFA signalling, pregnancy-induced beta cell proliferation and expansion was not precluded [51]. As we did not ablate all intraislet endothelial cells; however, we cannot unequivocally exclude that the residual islet endothelial cells suffice for and contribute to pregnancy-induced beta cell adaptation.

Beta cell proliferation can be supported by endothelium-derived factors and by VEGF-A, the latter in a dose- and time-dependent manner.

\section{Blood vessels in beta cell transplantation}

Transplantation of islet(-like) cells is a promising therapy for patients with type 1 diabetes [52]. Despite a significant improvement in metabolic outcome compared with the original Edmonton protocol, only $40-50 \%$ of patients remain insulinindependent 5 years after primary islet cell transplantation [53]. Although the mechanism of graft failure remains largely unknown, more than half of the grafted islets are destroyed during the first few days after transplantation [54]. Factors implicated in early graft loss include glucotoxicity, lipotoxicity, immune rejection, toxicity of the immune-suppressive regimens, instant bloodmediated inflammatory response (IBMIR), liver ischaemia and insufficient graft revascularisation [55]. Revascularisation of transplanted islets takes several weeks and remains suboptimal compared with that of endogenous islets [12]. Endothelial cells present in freshly isolated donor islets contribute to graft revascularisation though inosculation with the host vasculature. When donor mouse islets are cultured before transplantation, their revascularisation solely depends on the ingrowth of recipient microvessels [56].

Animal studies have demonstrated that strategies that promote early graft revascularisation and counteract liver ischaemia after transplantation can improve the outcome of islet transplantation. Overexpression of VEGF-A in grafted islets resulted in increased vascularisation and islet blood flow, increased beta cell survival and islet insulin content and better glucose control in recipient animals [57]. Similar observations were made in mice with streptozotocin-induced diabetes when the angiogenic factor Ang-1 was overexpressed in transplanted islets by adenovirusmediated gene delivery [58]. Interference with the angiostatic factor thrombospondin-1 in transplanted islets improved graft vascularisation and function, further supporting the idea that promoting early graft vascularisation in clinical islet transplantation could positively influence its outcome [59]. As genetic modulation of angiogenic or angiostatic factors in transplanted islets is precluded for clinical use, alternative strategies to improve islet revascularisation are needed. Indeed, vascular engraftment relates to transplantation outcome, as shown following preincubation of mouse or human islets with the proangiogenic factor prolactin before transplantation and by injection of prolactin during the first 7 days after islet transplantation beneath the renal capsule in mice [60]. Also, when proangiogenic cells were co-engrafted with islets, islet revascularisation was promoted. Rat aortic endothelial cells supported islet isograft survival [61], while human cord bloodderived endothelial progenitor cells improved porcine islet graft transplantation into diabetic nude mice by accelerating graft revascularisation [62]. Besides supporting graft revascularisation, endothelial (progenitor) cells have also been implicated in suppressing the detrimental effects of IBMIR [63]. Blood outgrowth endothelial cells (BOECs) are a late-outgrowing subtype of endothelial progenitor cells with beneficial effects on wound revascularisation and healing [64]. We showed that human BOECs improve islet graft function when co-transplanted with rat islets in immune-deficient diabetic mice [65]. BOEC recipients had a better metabolic outcome, less beta cell death, more proliferating beta cells in the graft, and higher graft-vessel and beta cell volumes. This advantage was maintained with BOECs derived from a patient with type 1 diabetes [65]. In an alternative approach, we circumvented the limited clinical translational potential of viral vector-mediated gene delivery, as discussed above, by liposome-mediated delivery of Vegfa mRNA to peripheral islet cells prior to transplantation. Vegfa mRNA transfection significantly improved both mouse and human islet graft revascularisation [66]. Such an approach using in vitro 
revascularisation and healing [64]. We showed that human BOECs improve islet graft function when co-transplanted with rat islets in immune-deficient diabetic mice [65]. BOEC recipients had a better metabolic outcome, less beta cell death, more proliferating beta cells in the graft, and higher graft-vessel and beta cell volumes. This advantage was maintained with BOECs derived from a patient with type 1 diabetes [65]. In an alternative approach, we circumvented the limited clinical translational potential of viral vector-mediated gene delivery, as discussed above, by liposome-mediated delivery of Vegfa mRNA to peripheral islet cells prior to transplantation. Vegfa mRNA transfection sig-

nificantly improved both mouse and human islet graft revascularisation [66]. Such an approach using in vitro transcribed mRNA for gene delivery has important advantages over classic gene therapy: (1) the overexpression is transient thus avoiding side effects of chronic VEGF-A overexpression such as increased vascular permeability and inflammation, and (2) the inherent risks of viral vector-based methods, such as insertional mutagenesis or vigorous immune reaction, are avoided. Since Vegfa mRNA transfection promoted vascularisation of mouse and human islets following transplantation, this approach represents an attractive strategy to improve islet cell transplantation protocols.

\section{Conclusion}

VEGF-A signalling from beta cells towards endothelial cells is crucial for endocrine vascular maintenance, while signals emanating from the endothelium appear critical for pancreas development, insulin secretion, beta cell proliferation and beta cell mass adaptation in response to changes in metabolic demand. Tight control of VEGF-A expression is essential for islet vessel maintenance and glucose homeostasis. VEGF-A loss of function results in islet hypovascularisation and impaired glucose tolerance, while prolonged VEGF overexpression results in islet hypervascularisation, beta cell death and overt diabetes. Restoration of intra-islet VEGF-A levels after its overexpression induces a process of beta cell regeneration. In the context of islet transplantation, an increase in the expression of pro-angiogenic factors, such as VEGF-A, or the co-engraftment with pro-angiogenic cells, increases graft revascularisation and significantly improves islet engraftment in preclinical studies.

Novel therapeutic strategies to restore the endogenous beta cell mass through beta cell regeneration or transplantation, could benefit from (1) further dissection of the mechanisms orchestrating beta cell regeneration upon VEGF-A modulation, and (2) clinical translation of experimental proangiogenic approaches to improve current islet transplantation protocols. Taken together, the evidence to date suggests that the vasculature may prove a suitable target for the development of new therapies for diabetes.

Acknowledgements We would like to acknowledge all researchers that contributed to the field. We would also like to thank our colleagues and members of the Beta Cell Neogenesis laboratory. We apologise to scientists whose work could not be highlighted because of space limitations.

Funding The authors acknowledge support by grants from the Research Foundation Flanders (FWO), the VUB Research Council, Stichting Diabetes Onderzoek Nederland, the European Union Sixth and Seventh Framework Program, the Wetenschappelijk Fonds Willy Gepts (WFWG) of the UZ Brussel and the European Foundation for the Study of Diabetes. WS is supported by a postdoctoral grant from Agence Nationale de la Recherche (Laboratoire d'Excellence Revive, Investissement d'Avenir; ANR-10-LABX-73).

Duality of interest The authors declare that there is no duality of interest associated with this manuscript.

Contribution statement WS and NDL were responsible for drafting the article. All authors revised it critically for important intellectual content. All authors approved the version to be published.

\section{References}

1. Ferrara N (2004) Vascular endothelial growth factor: basic science and clinical progress. Endocr Rev 25(4):581-611. https://doi.org/ 10.1210/er.2003-0027

2. Apte RS, Chen DS, Ferrara N (2019) VEGF in signaling and disease: beyond discovery and development. Cell 176(6):1248-1264. https://doi.org/10.1016/j.cell.2019.01.021

3. Matsumoto K, Yoshitomi H, Rossant J, Zaret KS (2001) Liver organogenesis promoted by endothelial cells prior to vascular function. Science 294(5542):559-563. https://doi.org/10.1126/science. 1063889

4. Yamamoto H, Yun EJ, Gerber HP, Ferrara N, Whitsett JA, Vu TH (2007) Epithelial-vascular cross talk mediated by VEGF-A and HGF signaling directs primary septae formation during distal lung morphogenesis. Dev Biol 308(1):44-53. https://doi.org/10.1016/j. ydbio.2007.04.042

5. Lammert E, Cleaver O, Melton D (2001) Induction of pancreatic differentiation by signals from blood vessels. Science 294(5542): 564-567. https://doi.org/10.1126/science.1064344

6. Yoshitomi H, Zaret KS (2004) Endothelial cell interactions initiate dorsal pancreas development by selectively inducing the transcription factor Ptfla. Development 131(4):807-817. https://doi.org/10. 1242/dev.00960

7. Jacquemin P, Yoshitomi H, Kashima Y, Rousseau GG, Lemaigre FP, Zaret KS (2006) An endothelial-mesenchymal relay pathway regulates early phases of pancreas development. Dev Biol 290(1): 189-199. https://doi.org/10.1016/j.ydbio.2005.11.023

8. Pierreux CE, Cordi S, Hick AC et al (2010) Epithelial: endothelial cross-talk regulates exocrine differentiation in developing pancreas. 
13. Brissova M, Shostak A, Fligner CL et al (2015) Human islets have fewer blood vessels than mouse islets and the density of islet vascular structures is increased in type 2 diabetes. J Histochem Cytochem 63(8):637-645. https://doi.org/10.1369/ 0022155415573324

14. Virtanen I, Banerjee M, Palgi J et al (2008) Blood vessels of human islets of Langerhans are surrounded by a double basement membrane. Diabetologia 51(7):1181-1191. https://doi.org/10.1007/ s00125-008-0997-9

15. Kragl M, Schubert R, Karsjens H et al (2016) The biomechanical properties of an epithelial tissue determine the location of its vasculature. Nat Commun 7(1):13560. https://doi.org/10.1038/ ncomms 13560

16. Brissova M, Shostak A, Shiota M et al (2006) Pancreatic islet production of vascular endothelial growth factor-A is essential for islet vascularization, revascularization, and function. Diabetes 55(11): 2974-2985. https://doi.org/10.2337/db06-0690

17. Iwashita N, Uchida T, Choi JB et al (2007) Impaired insulin secretion in vivo but enhanced insulin secretion from isolated islets in pancreatic beta cell-specific vascular endothelial growth factor-A knock-out mice. Diabetologia 50(2):380-389. https://doi.org/10. 1007/s00125-006-0512-0

18. Toyofuku Y, Uchida T, Nakayama S et al (2009) Normal islet vascularization is dispensable for expansion of beta-cell mass in response to high-fat diet induced insulin resistance. Biochem Biophys Res Commun 383(3):303-307. https://doi.org/10.1016/j. bbrc.2009.03.138

19. D'Hoker J, De Leu N, Heremans Y et al (2013) Conditional hypovascularization and hypoxia in islets do not overtly influence adult beta-cell mass or function. Diabetes 62(12):4165-4173. https://doi.org/10.2337/db12-1827

20. Jansson L, Andersson A, Bodin B, Kallskog O (2007) Pancreatic islet blood flow during euglycaemic, hyperinsulinaemic clamp in anaesthetized rats. Acta Physiol (Oxf) 189(4):319-324. https://doi. org/10.1111/j.1748-1716.2006.01666.x

21. Xiao X, Guo P, Chen Z et al (2013) Hypoglycemia reduces vascular endothelial growth factor A production by pancreatic beta cells as a regulator of beta cell mass. J Biol Chem 288(12):8636-8646. https://doi.org/10.1074/jbc.M112.422949

22. Nyman LR, Ford E, Powers AC, Piston DW (2010) Glucosedependent blood flow dynamics in murine pancreatic islets in vivo. Am J Physiol Endocrinol Metab 298(4):E807-E814. https://doi.org/10.1152/ajpendo.00715.2009

23. Konishi M, Sakaguchi M, Lockhart SM et al (2017) Endothelial insulin receptors differentially control insulin signaling kinetics in peripheral tissues and brain of mice. Proc Natl Acad Sci U S A 114(40):E8478-E8487. https://doi.org/10.1073/pnas.1710625114

24. Obata A, Kimura T, Obata Y et al (2019) Vascular endothelial PDPK1 plays a pivotal role in the maintenance of pancreatic beta cell mass and function in adult male mice. Diabetologia 62(7): 1225-1236. https://doi.org/10.1007/s00125-019-4878-1

25. Nolan CJ, Damm P, Prentki M (2011) Type 2 diabetes across generations: from pathophysiology to prevention and management. Lancet 378(9786):169-181. https://doi.org/10.1016/S01406736(11)60614-4

26. Tabit CE, Chung WB, Hamburg NM, Vita JA (2010) Endothelial dysfunction in diabetes mellitus: molecular mechanisms and clinical implications. Rev Endocr Metab Disord 11(1):61-74. https:// doi.org/10.1007/s11154-010-9134-4

27. Li X, Zhang L, Meshinchi S et al (2006) Islet microvasculature in islet hyperplasia and failure in a model of type 2 diabetes. Diabetes 55(11):2965-2973. https://doi.org/10.2337/db06-0733

28. Mizuno A, Noma Y, Kuwajima M, Murakami T, Zhu M, Shima K (1999) Changes in islet capillary angioarchitecture coincide with impaired B cell function but not with insulin resistance in male Otsuka-Long-Evans-Tokushima fatty rats: dimorphism of the diabetic phenotype at an advanced age. Metabolism 48(4):477483. https://doi.org/10.1016/S0026-0495(99)90107-5

29. Agudo J, Ayuso E, Jimenez V et al (2012) Vascular endothelial growth factor-mediated islet hypervascularization and inflammation contribute to progressive reduction of beta-cell mass. Diabetes 61(11):2851-2861. https://doi.org/10.2337/db12-0134

30. Brissova M, Aamodt K, Brahmachary P et al (2014) Islet microenvironment, modulated by vascular endothelial growth factor-A signaling, promotes beta cell regeneration. Cell Metab 19(3):498-511. https://doi.org/10.1016/j.cmet.2014.02.001

31. De Leu N, Heremans Y, Coppens V et al (2014) Short-term overexpression of VEGF-A in mouse beta cells indirectly stimulates their proliferation and protects against diabetes. Diabetologia 57(1):140-147. https://doi.org/10.1007/s00125-013-3076-9

32. Shah P, Lueschen N, Ardestani A et al (2016) Angiopoetin-2 signals do not mediate the hypervascularization of islets in type 2 diabetes. PLoS One 11(9):e0161834. https://doi.org/10.1371/ journal.pone. 0161834

33. Hogan MF, Liu AW, Peters MJ et al (2017) Markers of islet endothelial dysfunction occur in male B6.BKS(D)-Leprdb/J mice and may contribute to reduced insulin release. Endocrinology 158(2): 293-303. https://doi.org/10.1210/en.2016-1393

34. Lacraz G, Giroix MH, Kassis N et al (2009) Islet endothelial activation and oxidative stress gene expression is reduced by IL-1Ra treatment in the type 2 diabetic GK rat. PLoS One 4(9):e6963. https://doi.org/10.1371/journal.pone.0006963

35. Tan KC, Chow WS, Ai VH, Metz C, Bucala R, Lam KS (2002) Advanced glycation end products and endothelial dysfunction in type 2 diabetes. Diabetes Care 25(6):1055-1059. https://doi.org/ 10.2337/diacare.25.6.1055

36. Lan KC, Chiu CY, Kao CWH et al (2015) Advanced glycation endproducts induce apoptosis in pancreatic islet endothelial cells via NF-kappaB-activated cyclooxygenase-2/prostaglandin E2 up-regulation. PLoS One 10(4):e0124418. https://doi.org/10.1371/journal. pone. 0124418

37. Herold KC, Vignali DA, Cooke A, Bluestone JA (2013) Type 1 diabetes: translating mechanistic observations into effective clinical outcomes. Nat Rev Immunol 13(4):243-256. https://doi.org/10. $1038 /$ nri3422

38. Jansen A, Homo-Delarche F, Hooijkaas H, Leenen PJ, Dardenne M, Drexhage HA (1994) Immunohistochemical characterization of monocytes-macrophages and dendritic cells involved in the initiation of the insulitis and beta-cell destruction in NOD mice. Diabetes 43(5):667-675. https://doi.org/10.2337/diab.43.5.667

39. Irving-Rodgers HF, Ziolkowski AF, Parish CR et al (2008) Molecular composition of the peri-islet basement membrane in NOD mice: a barrier against destructive insulitis. Diabetologia 51(9):1680-1688. https://doi.org/10.1007/s00125-008-1085-x

40. Korpos E, Kadri N, Kappelhoff R et al (2013) The peri-islet basement membrane, a barrier to infiltrating leukocytes in type 1 diabetes in mouse and human. Diabetes 62(2):531-542. https://doi.org/ $10.2337 / \mathrm{db} 12-0432$

41. Savinov AY, Wong FS, Stonebraker AC, Chervonsky AV (2003) Presentation of antigen by endothelial cells and chemoattraction are required for homing of insulin-specific CD8+ T cells. J Exp Med 197(5):643-656. https://doi.org/10.1084/jem.20021378

42. Sandor AM, Lindsay RS, Dyjack N et al (2019) CD11c(+) cells are gatekeepers for lymphocyte trafficking to infiltrated islets during type 1 diabetes. Front Immunol 10:99. https://doi.org/10.3389/ fimmu.2019.00099

43. Villalta SA, Lang J, Kubeck S et al (2013) Inhibition of VEGFR-2 reverses type 1 diabetes in NOD mice by abrogating insulitis and restoring islet function. Diabetes 62(8):2870-2878. https://doi.org/ $10.2337 / \mathrm{db} 12-1619$

44. Akirav EM, Baquero MT, Opare-Addo LW et al (2011) Glucose and inflammation control islet vascular density and beta-cell 
function in NOD mice: control of islet vasculature and vascular endothelial growth factor by glucose. Diabetes 60(3):876-883. https://doi.org/10.2337/db10-0793

45. Canzano JS, Nasif LH, Butterworth EA, Fu DA, Atkinson MA, Campbell-Thompson M (2018) Islet microvasculature alterations with loss of beta-cells in patients with type 1 diabetes. J Histochem Cytochem 22155418778546

46. Nikolova G, Jabs N, Konstantinova I et al (2006) The vascular basement membrane: a niche for insulin gene expression and beta cell proliferation. Dev Cell 10(3):397-405. https://doi.org/10.1016/ j.devcel.2006.01.015

47. Kaido T, Yebra M, Cirulli V, Montgomery AM (2004) Regulation of human beta-cell adhesion, motility, and insulin secretion by collagen IV and its receptor alphal beta1. J Biol Chem 279(51):5376253769. https://doi.org/10.1074/jbc.M411202200

48. Guney MA, Petersen CP, Boustani A et al (2011) Connective tissue growth factor acts within both endothelial cells and beta cells to promote proliferation of developing beta cells. Proc Natl Acad Sci U S A 108(37):15242-15247. https://doi.org/10.1073/pnas. 1100072108

49. Riley KG, Pasek RC, Maulis MF et al (2015) Connective tissue growth factor modulates adult beta-cell maturity and proliferation to promote beta-cell regeneration in mice. Diabetes 64(4):1284-1298. https://doi.org/10.2337/db14-1195

50. Johansson M, Mattsson G, Andersson A, Jansson L, Carlsson PO (2006) Islet endothelial cells and pancreatic beta-cell proliferation: studies in vitro and during pregnancy in adult rats. Endocrinology 147(5):2315-2324. https://doi.org/10.1210/en.2005-0997

51. Staels W, Heremans Y, Leuckx G et al (2017) Conditional islet hypovascularisation does not preclude beta cell expansion during pregnancy in mice. Diabetologia 60(6):1051-1056. https://doi.org/ 10.1007/s00125-017-4243-1

52. Shapiro AM, Pokrywczynska M, Ricordi C (2017) Clinical pancreatic islet transplantation. Nat Rev Endocrinol 13(5):268-277. https://doi.org/10.1038/nrendo.2016.178

53. Barton FB, Rickels MR, Alejandro R et al (2012) Improvement in outcomes of clinical islet transplantation: 1999-2010. Diabetes Care 35(7):1436-1445. https://doi.org/10.2337/dc12-0063

54. Biarnes M, Montolio M, Nacher V, Raurell M, Soler J, Montanya E (2002) Beta-cell death and mass in syngeneically transplanted islets exposed to short- and long-term hyperglycemia. Diabetes 51(1):6672. https://doi.org/10.2337/diabetes.51.1.66

55. Harlan DM, Kenyon NS, Korsgren O, Roep BO (2009) Immunology of diabetes $\mathrm{S}$ : current advances and travails in islet transplantation. Diabetes 58(10):2175-2184. https://doi.org/10. 2337/db09-0476
56. Nyqvist D, Speier S, Rodriguez-Diaz R et al (2011) Donor islet endothelial cells in pancreatic islet revascularization. Diabetes 60(10):2571-2577. https://doi.org/10.2337/db10-1711

57. Zhang L, Vincent MA, Richards SM, Clerk LH, Rattigan S, Clark MG, Barrett EJ (2004) Insulin sensitivity of muscle capillary recruitment in vivo. Diabetes 53(2):447-453. https://doi.org/10.2337/ diabetes.53.2.447

58. Su D, Zhang N, He J et al (2007) Angiopoietin-1 production in islets improves islet engraftment and protects islets from cytokineinduced apoptosis. Diabetes 56(9):2274-2283. https://doi.org/10. 2337/db07-0371

59. Olerud J, Johansson M, Lawler J, Welsh N, Carlsson PO (2008) Improved vascular engraftment and graft function after inhibition of the angiostatic factor thrombospondin-1 in mouse pancreatic islets. Diabetes 57(7):1870-1877. https://doi.org/10.2337/db07-0724

60. Johansson M, Olerud J, Jansson L, Carlsson PO (2009) Prolactin treatment improves engraftment and function of transplanted pancreatic islets. Endocrinology 150(4):1646-1653. https://doi.org/10. 1210/en.2008-1318

61. Song HJ, Xue WJ, Li Y et al (2010) Prolongation of islet graft survival using concomitant transplantation of islets and vascular endothelial cells in diabetic rats. Transplant Proc 42(7):26622665. https://doi.org/10.1016/j.transproceed.2010.06.003

62. Kang S, Park HS, Jo A et al (2012) Endothelial progenitor cell cotransplantation enhances islet engraftment by rapid revascularization. Diabetes 61(4):866-876. https://doi.org/10.2337/db10-1492

63. Kim JH, Oh BJ, Lee HN, Park HS, Park SG, Park KS (2011) Endothelial colony-forming cell coating of pig islets prevents xenogeneic instant blood-mediated inflammatory reaction. Cell Transplant 20(11-12):1805-1815. https://doi.org/10.3727/ $096368911 X 566154$

64. Hendrickx B, Verdonck K, Van den Berge S et al (2010) Integration of blood outgrowth endothelial cells in dermal fibroblast sheets promotes full thickness wound healing. Stem Cells 28(7):11651177. https://doi.org/10.1002/stem.445

65. Coppens V, Heremans Y, Leuckx G et al (2013) Human blood outgrowth endothelial cells improve islet survival and function when co-transplanted in a mouse model of diabetes. Diabetologia 56(2):382-390. https://doi.org/10.1007/s00125-012-2754-3

66. Staels W, Verdonck Y, Heremans Y et al (2018) Vegf-A mRNA transfection as a novel approach to improve mouse and human islet graft revascularisation. Diabetologia 61(8):1804-1810. https://doi. org/10.1007/s00125-018-4646-7

Publisher's note Springer Nature remains neutral with regard to jurisdictional claims in published maps and institutional affiliations. 